\title{
MERCANTILIZAÇÃO DA LINGUAGEM NO CAPITALISMO RECENTE: DIVERSIDADES E MOBILIDADES
}

\author{
LANGUAGE COMMODIFICATION IN LATE CAPITALISM: \\ DIVERSITIES AND MOBILITIES
}

\author{
Pedro de Moraes Garcez* \\ Neiva Maria Jung (UEM) **
}

$\mathrm{Na}$ assim chamada "nova economia globalizada", em concomitância com a expansão do capital, avanços tecnológicos maciços produziram possibilidades inéditas de circulação de informações e recursos, além de deslocamentos de populações que podem assumir identidades pós- ou transnacionais (DE FINA; PERRINO, 2013). De outro lado, a lógica da globalização e o fracionamento das cadeias produtivas aprofundaram as diferenças sociais; e a linguagem ${ }^{1}$ tornou-se parte altamente relevante nesse processo de estratificação, muitas vezes mediando processos de categorização que organizam e legitimam a desigualdade (HELLER, 2011). Tais fenômenos trouxeram novos desafios para os estudos da linguagem interessados em compreender o que se passa em cenários de grande diversidade sociolinguística, mais evidente em alguns do que em outros. Além disso, a pandemia da Covid-19 tornou ainda mais complexa a compreensão das contradições do capitalismo e suas relações com a linguagem nesses cenários, ao provocar alterações súbitas nas dinâmicas interacionais e na mobilidade das pessoas.

O presente dossiê ${ }^{2}$ reúne trabalhos que examinam conceitos que entraram para a discussão em Linguística Aplicada e Sociolinguística nos últimos 15 anos, em arcabouços conceituais contemporâneos que põem em xeque ideologias linguísticas como a noção moderna de língua como sistema claramente delimitado e, em vez disso, instauram uma "abordagem de repertórios" para o estudo tanto das situações de diversidade (BLOMMAERT; RAMPTON, 2011) quanto da educação em linguagem na contemporaneidade (JAFFE, 2011). Em particular, examinam-se ideologias de linguagem e de poder na complexa intersecção entre capitalismo, nacionalismo e colonialismo desde o século $\mathrm{XV}$, passando pela formação do capitalismo industrial e do Estado-nação moderno até os desafios às ideias dominantes de linguagem e identidade no capitalismo recente (HELLER; MCELHINNY, 2017). Em destaque está a proposta de Heller e colaboradores de que estaríamos dando passos na direção do pós-nacionalismo (HELLER, 2011), em que recursos linguísticos instrumentais e simbólicos estariam passando a figurar em trocas econômicas no que poderia

* Universidade Federal do Rio Grande do Sul (UFRGS), Porto Alegre, RS, Brasil. pedrom.garcez@ufrgs.br Orcid: https://orcid.org/0000-0001-8642-678X

** Universidade Estadual de Maringá (UEM), Maringá, PR, Brasil. neiva.jung@gmail.com Orcid: https://orcid.org/0000-0002-7249-7816

1. Assumimos que nosso objeto de interesse acadêmico é a linguagem, fenômeno multissemiótico. Evitamos assim formas como "língua(gem)", e empregamos "língua" ocasionalmente em referência a entidades cuja realidade entendemos ser eminentemente social, conforme de algum modo demonstrado pelos atores sociais que as invocam, muitas vezes exatamente pela nomeação de itens de repertório linguístico. Na nomeação de línguas, optamos por grafias convencionais, iniciais minúsculas e concordâncias de praxe, sem distinção, e recomendamos aos autores dos artigos que também procedessem assim (ver FIORIN, PETER, 2007, p. 10-11)

2. Este dossiê responde ao convite conjunto da Associação de Linguística Aplicada do Brasil (ALAB) e de TLA para celebrar os 30 anos da ALAB. O ímpeto reflexivo que resulta no conjunto de trabalhos reunidos aqui partiu inicialmente das atividades em torno da visita acadêmica que a linguista sociocultural canadense Monica Heller fez à USP, à UFRGS e à UEMS em abril de 2019. [Agradecemos aos colegas Walkyria Montemór (USP) e Ruberval Maciel (UEMS), assim como Ceres Victora e Ruben Oliven (PPG-Antropologia Social/ UFRGS), pela parceria e pelos apoios que tornaram possível aquela visita.] Em novembro daquele ano, um bom número dos colegas que participaram do curso livre ministrado por Heller em Porto Alegre responderam à nossa chamada para apresentar reflexões a partir das suas pesquisas que pudessem ser sistematizadas em alguma medida com base no que lemos e discutimos àquela altura. Tendo a colega Inês Signorini (Unicamp) como debatedora (a quem agradecemos a colaboração e os comentários críticos francos), isso se deu no simpósio "Linguagem, capitalismo e colonialismo: diversidade e mobilidade" por ocasião do III SIMVALE - Simpósio de Variação Linguística e Ensino, que teve lugar na Universidade Estadual de Maringá (UEM). Ao final do encontro, acordamos em fazer esforços para redigir os trabalhos e qualificar nossas reflexões para que excedessem a mera ilustração e trouxessem uma contribuição em termos de compreensão de práticas de linguagem e seus significados sociais e simbólicos, superando assim a praxe entre nós de ouvir expoentes da literatura acadêmica internacional para depois relatarmos nossas reflexões sobre o que disseram com base em dados das nossas realidades, sem mais. Seis daqueles trabalhos resultam em artigos publicados aqui, aos quais se juntaram as oportunas contribuições de Tatiana Martins Gabas e de Vanessa de Oliveira Andreotti, Jhuliane Evelyn da Silva e Clarissa Menezes Jordão. 
ser visto como mercantilização ${ }^{3}$ da linguagem (DUCHÊNE; HELLER, 2012; HELLER; DUCHÊNE, 2012, 2016) - com alterações cruciais na visão de linguagem como marca de identidade (pride, orgulho) para linguagem também como habilidade ou valor comercial agregado (profit, lucro).

\section{LINGUÍSTICA APLICADA, ECONOMIA POLÍTICA, JUSTIÇA SOCIAL E DISTRIBUIÇÃO}

$\mathrm{Na}$ trajetória interdisciplinar da Linguística Aplicada, a atenção a valores nomeadamente econômicos tem sido pouco comum. Com efeito, mesmo em propostas indisciplinares, é raro que a busca por "criar inteligibilidades sobre a vida contemporânea ao produzir conhecimento" sobre linguagem (MOITA-LOPES, 2006, p. 85) trate expressamente de dinâmicas econômicas no eixo da distribuição de recursos e bens (FRASER, 1996) ${ }^{4},{ }^{5}$. Este dossiê faz isso pela ótica de uma perspectiva crítica que, compartilhando com a Linguística Aplicada mais amplamente a preocupação com justiça social, examina e explica como as dinâmicas de inclusão e exclusão funcionam em contextos e momentos específicos, identificando recursos linguísticos em circulação, em disputa, e sua valoração, revelando as consequências desses processos, em termos de quem controla o acesso a recursos, quem lhes atribui valores, quem se beneficia ou sofre com essas dinâmicas (HELLER, 2011).

Em boa medida, isso requer trazer elementos de Economia Política ${ }^{6}$ para a discussão, tal como propõem Block, Gray e Holborow (2012) quando afirmam ser crucial "para qualquer análise bem apanhada de linguagem ou de questões ligadas à linguagem no mundo de hoje" ter em vista os modos "como fatores sociais, políticos e econômicos se relacionam no quadro de uma economia capitalista" (p. iii). Para isso, precisamos ainda de conhecimento de História para entender como foi que chegamos ao presente que vivemos e, quiçá, vislumbrar caminhos menos distópicos para o porvir (ver ANDRIOTTI; SILVA; JORDÃO, neste dossiê). Contudo, nosso propósito aqui não é desenvolver erudição sobre as compreensões oferecidas pela Economia Política como campo de estudo ou pela História como disciplina, mas sim "seguir os dados" (HELLER; PIETIKÄINEN; PUJOLAR, 2018) para compreender linguagem e sua articulação com o que se passa na economia política como campo de ação na vida vivida de atores sociais contemporâneos. Para tanto, nos valemos do trabalho ${ }^{7}$ de quem revisa fontes bibliográficas seminais e daí nos dedicamos, mais informada e centralmente, a examinar dados de ação pelo uso da linguagem, isto é, na vida social situada, com foco detido sobre ocasiões em que a própria linguagem surge como terreno de tensões e de disputas (ver OLIVEN; GARCEZ, 2020). Resulta uma (socio)linguística sociocultural, não muito diferente do que nos parece que já se faz entre nós na Linguística Aplicada há algum tempo. A interlocução que projetamos centralmente aqui é, portanto, com quem reflete sobre linguagem e vem talvez percebendo algo no ar, que, apesar de não estar ainda totalmente articulado, demonstra uma complexidade multifacetada que exige muitas articulações e desafia a nossa compreensão. Aqui oferecemos formulações dessa sensação, explicitada na seção seguinte, em uma chave que nos parece relevante, ainda que de certo parcial e insuficiente. Os artigos que compõem o dossiê fazem mais, é claro, ao

3. Trata-se da configuração de elementos linguísticos como commodities, o que em inglês é referido pelo termo "commodification". Optamos por empregar "mercantilização", uma vez que "comodificação" não parece reter a relação com commodity (além de sugerir modificações concomitantes), e "comoditização" tem sentidos bem distintos em Administração.

4. Fraser (1996) contrasta o paradigma de justiça social que se configurou em torno de reconbecimento ("de perspectivas de minorias étnicas, 'raciais' e sexuais, além da diferença de gênero", p. 3) e o paradigma mais antigo, de (re) distribuição igualitária ("de recursos e bens ... do Norte para o Sul, dos ricos para os pobres, dos proprietários para os trabalhadores", p. 4). Argumenta em favor do que chama de concepção bivalente de justiça que "abrange distribuição e reconhecimento sem reduzir um ao outro [..., ] não trata o reconhecimento como bem a ser distribuído, nem distribuição como expressão de reconhecimento[, mas] como perspectivas e dimensões distintas de justiça [...] em uma estrutura ampla maior" (p. 10) de "paridade participativa" (p. 25)

5. As passagens reproduzidas em citação de obras publicadas originalmente em inglês aparecem neste artigo em nossa tradução informal para os propósitos deste trabalho.

6. Segundo Block, Gray e Holborow (2012), a Economia Política, conforme se entende isso hoje nas Ciências Sociais, "enfatiza a inter-relação dos processos políticos e econômicos [...] para focar o conjunto da atividade econômica, a alocação de recursos, a acumulação de capital, a desigualdade de renda, a globalização e o poder imperial [...] primeiro, como disciplina acadêmica [...] e segundo como caminho para a interdisciplinaridade que combina ramos da economia e da política, a fim de compreender como as instituições sociais, suas atividades e o capitalismo influenciam-se mutuamente de várias maneiras" (p. 1-2).

7. Um percurso de leitura nessa empreitada poderia incluir os trabalhos seminais de Anderson (2006[1983]/2008), Hobsbawm (1990), Bauman e Briggs (2003), e Harvey $(2005,2014)$, e, entre outros trabalhos recentes no âmbito da Linguística Aplicada/Sociolinguística, as instigantes revisões de literatura em Block, Halborow e Gray (2012), Block (2018), Chun (2017), Moita-Lopes (2013a, 2013b, 2015), Signorini $(2013,2015)$, entre outros. Heller e McElhinny (2017) oferecem um apanhado geral para, como dizem, seguindo a proposta de Raymond Williams, caminharmos de volta para o futuro. 
oferecerem descrições e explicações a partir desse arcabouço que, esperamos, forme um panorama que abre novas vistas, aprofunda a compreensão e fomenta novas interlocuções.

\section{LINGUAGEM E 0 ESTADO-NAÇÃO NO ESTÁGIO MAIS RECENTE DO REGIME DE REGULAÇÃO CAPITALISTA: MENOS ORGULHO, MAIS VALIA}

$\mathrm{Na}$ empreitada que resulta neste dossiê, contudo e portanto, atentamos especialmente para o que Heller e seus colaboradores vêm apontando (HELLER, 2002, 2005, 2010; HELLER; DUCHÊNE, 2012, 2016), nomeadamente, o amplo surgimento de elementos discursivos que tratam de linguagem e cultura primordialmente em termos econômicos. Isso desloca a linguagem do eixo das relações identitárias entre sujeito e "língua", típicas do nacionalismo que marcou o capitalismo industrial, para incorporar relações econômicas entre sujeito e linguagem. Nesses movimentos, repertórios sociolinguísticos múltiplos e mesmo multifacetados são re/des/valorizados como elementos simbólicos relevantes, seja como "soft skills" (URCIUOLI, 2008) que o trabalhador "flexível" e muitas vezes precarizado oferece aos "mercados", seja como "valor agregado" ao que pode ser vendido ou de algum modo rentabilizado, quando parece que tudo - da água à identidade - pode ser mercantilizado.

Neste momento histórico em que estamos, de capitalismo tardio, pós-industrial, para muitos o Estado se justifica apenas por estar "a serviço do desenvolvimento econômico", não necessariamente do bem-estar dos "seus cidadãos" "legítimos", e o sistema de regulação nacional dos mercados parece ter sido levado ao limite, e talvez mesmo além. Disso seguem tensões no regime dos Estados-nação que por sua vez "dão origem a novos tropos discursivos nos quais a linguagem desempenha um papel particularmente central, não apenas por seu papel na regulação e legitimação de espaços político-econômicos, mas também por conta do surgimento do setor terciário como elemento definidor da nova economia globalizada" (HELLER; DUCHÊNE, 2012, p. 3), uma vez que esse é um setor de atividades marcadamente linguageiras (como call centers, por exemplo).

Ao tratar dos termos "globalização", "nova economia" e "neoliberalismo", Heller (2011) ressalta a importância dos modos de integração dos mercados locais e regionais, que passa a se dar mediante "regimes de regulação baseados na cooperação econômica em vez do colonialismo" (p. 19) explícito, com circulação de pessoas, bens e informações cada vez mais intensa. No neoliberalismo, o Estado, não mais "de bem estar social", retorna ao seu papel de facilitar a construção e manutenção de mercados administrados pelo setor privado e para o setor privado, agora em redes supranacionais, ainda que tenha que ter algum compromisso com os interesses dos cidadãos sobre aqueles considerados não cidadãos. Segundo a autora, o elemento novo é a tal "nova economia", que diz respeito ao

surgimento de novos regimes de regulação do trabalho (flexibilidade, responsabilidade individual); de modos de produções cada vez mais mediados, seja tecnologicamente, linguisticamente ou culturalmente; do crescimento do setor terciário; e de maior ênfase em valor agregado simbólico, bem como de aberturas para nichos de mercado locais articulados com os globais de maneiras complexas (p. 20).

Essa percepção brutal parece clara pelo olhar que temos agora. Contudo, mesmo para observadores atentos como David Harvey, demorou até ser possível formular esse estado de coisas que era reconhecível durante algum tempo apenas nos modos que Williams (1973[1998]) chamou de "estruturas de sentimentos" (structures of feeling), isto é, uma sensação de mudança histórica ainda difusa e, portanto, envolta também em grande indeterminação. Hoje parece claro que, já desde os anos $1970^{8}$, processos interconectados de mudança desestabilizaram a capacidade do Estado-nação de regular unitariamente os mercados (a produção de bens e serviços e de produtores e consumidores) na sua jurisdição e dentro das "suas fronteiras", ou de controlar a produção e a circulação de discursos de legitimação, assim como a circulação do próprio capital e, às vezes, do trabalho. No neoliberalismo9 , o Estado aceita afastar-se da

8. Com o privilégio de poder considerar o passado, marcos notáveis são o choque Nixon entre 1971-1973 (uma série de medidas econômicas levadas a cabo pelo Presidente dos Estados Unidos Richard Nixon, em 1971, com destaque para o cancelamento unilateral da conversão do dólar em ouro, resultando na substituição, em 1973, do sistema Bretton Woods de gerenciamento financeiro internacional que vigorava desde 1944 para um regime baseado no câmbio flutuante, que opera até hoje), a expansão da Escola de Chicago de pensamento econômico e o seu experimento chileno, as reformas econômicas que tornaram a China capitalista e a famosa frase de Margaret Thatcher em entrevista ao Sunday Times em maio de 1981 "A economia é o método; o objetivo é mudar o coração e a alma".

9. Conforme Block (2017), "o neoliberalismo pode ser entendido como a encarnação mais recente do capitalismo, mas desta vez por meios mais eficientes em circunstâncias mais intensamente e extensivamente globalizadas e mais tecnologicamente avançadas" (p. 37) e envolve uma série de fenômenos, atividades e comportamentos colaterais", como a "redução, ou mesmo eliminação completa, de financiamento governamental dos serviços públicos, os já conhecidos 'cortes' de gastos com educação, assistência médica, transporte, habitação e 
regulamentação do setor privado e facilitar a expansão e a circulação globais do capital, retendo assim alguma medida de controle em adaptação às novas condições.

De particular interesse para os estudos da linguagem que destacamos aqui, "orgulho" já não funciona mais tão bem como o principal tropo da legitimação para as desigualdades que o capitalismo cria e recria e que o Estado-nação gerencia; em vez disso, a capacidade de o Estado de facilitar o crescimento da "nova economia globalizada" depende de sua capacidade de legitimar discursos de "lucro". Nisso, a linguagem está envolvida centralmente de duas maneiras principais, como fonte de valor agregado simbólico e como modo de gestão de redes globais. Em máxima suma, o capitalismo tardio muda os regimes de mercado e, portanto, reposiciona os atores sociais no que diz respeito ao seu acesso ao capital. A mudança é desigual, mas sua dinâmica é familiar; atores localizados diferencialmente - entre privilégios consolidados ou instáveis e vulnerabilidades históricas ou contingentes - enfrentam as indeterminações de múltiplas maneiras, resultando muitas vezes em precariedades, como atestam os diversos artigos do dossiê.

De certo há mais continuidade do que ruptura na nova economia globalizada, mas parece que estamos nos aproximando dos limites dos regimes linguísticos nacionais (ou nacionais linguísticos) para organizar nossas vidas ${ }^{10}$. Em vez disso, vamos encontrando sistemas que se fragmentam em fluxos circulantes e agentividade local abrindo buracos na reprodução institucional e esgarçamento da fronteira entre autenticidade e artifício (ver ALBERTONI; JUNG; MACHADO E SILVA; GUEROLA; LUCENA, neste dossiê). Entretanto, cabe salientar que o regime econômico capitalista contemporâneo sustentado por discursos do neoliberalismo se assenta na construção do sujeito - os corações e as almas a que se referia Margaret Thatcher em 1981 - cuja identidade central passa a girar em torno da sua condição de consumidor (ver FONSECA, neste dossiê) - e parece se calcar em um regime político de concentração de poder nas classes políticas, sem falar na crescente concentração de poder econômico e do aumento de contingentes populacionais "excedentes".

\section{FLAGRANTES DE MERCANTILIZAÇÃO DE LINGUAGEM: 0 DOSSIÊ"11}

Observando de perto casos específicos que se desenrolam no terreno da linguagem na nossa região do planeta, os autores dos trabalhos que compõem este dossiê trataram de flagrar e compreender as contradições nos regimes de legitimação do capitalismo, sobretudo aquelas que se dão com base em ideologias de linguagem, com alguma ambição de explicar que dinâmicas estão sendo mobilizadas e para que fins. Boa parte do esforço analítico relatados nos artigos diz respeito a trazer à luz o que, seguindo Irvine (2021), entendemos como "trabalho de ideologia de linguagem"12, isto é, "as ações sociais de estabelecimento de alianças entre certos atores, por contrastes com outros atores não nomeados, mediante formulações que começam como pressuposições, engajam processos semióticos e mobilizam projetos sociais" em um mundo social cambiante, formulações que podem perdurar, mas podem ser também cambiantes elas próprias. Seguindo Heller e Duchêne (2012), buscaram ter em vista como as ideologias de linguagem figuram na neutralização de uma contradição central do Estado-nação, que opõe a divisão do trabalho à igualdade de oportunidades,

primeiro [...] como meio importante de construir simultaneamente homogeneidade e fronteiras, trazendo algumas pessoas para a cidadania por meio da aprendizagem de línguas e excluindo outras [... i] segundo, [ao] fortalece[r] a capacidade da democracia liberal de mistificar e justificar a estratificação social, estabelecendo hierarquias de valores linguísticos que são, em princípio, democraticamente acessíveis [...] construídas por meio de mecanismos de seleção social, legitimados por discursos que localizam o fracasso no plano da fibra moral ou das características físicas dos excluídos, ao invés de no desejo dos poderosos de permanecer assim (p. 4).

assim por diante [ ], a privatização parcial ou total de muitos desses serviços públicos, [...] regimes regressivos de imposto de renda, [...] desregulamentação parcial e/ou total dos mercados financeiros, [...] desregulamentação territorial, como terceirização e off-shorization" [deslocar produção ou capital para outras jurisdições para reduzir custos ou tributação] (p. 38). Para Heller e McElhinny (2017), o termo diz respeito aos "discursos legitimadores ligados ao desmantelamento do estado de bem-estar social e à regulação pelo Estado-nação dos mercados nacionais necessários para que tais formas de globalização sejam possíveis" (p. 231).

10. Sinais claros disso são a celebração do multilinguismo - preferencialmente em repertórios que incluem inglês e uma outra língua tipográfica prestigiosa (em geral outra língua colonial), e o que mais estiver acessível é lucro (ver GABAS, neste dossiê) - e a abertura para reivindicação de espaço para "línguas pequenas", muitas vezes ainda com base em discursos de orgulho, mas em geral deslizando para discursos de lucro (ver JUNG; MACHADO E SILVA, neste dossiê).

11. Além dos autores dos artigos e da entrevista que compõem este dossiê, manifestamos nosso agradecimento aos colegas que responderam à chamada de trabalhos, aos que contribuíram para a composição deste dossiê na condição de avaliadores externos dos trabalhos e à equipe editorial da TLA.

12. Ver Gal e Irvine (2019) para detalhamento e discussão. 
Essas mudanças vão também expondo os flancos da mais hegemônica das ideologias de linguagem, a que associa identidade linguística a uma língua idealizada, sistema-delimitado-e-íntegro, como critério de legitimidade para a cidadania plena, de pertencimento ao Estado. Vai assim ficando evidente que a descoberta, ou a invenção, de "língua como sistema", que se deu pela "extração da linguagem do mundo social" (ver HELLER em GARCEZ; OLIVEN, 2020), que resulta na concepção hoje hegemônica de "língua", surgiu em paralelo à criação do Estadonação como entidade integral, indissolúvel, fixada no tempo e no espaço, delimitada por fronteiras, isolado dos outros Estados-nação. Com esse conceito "útil" de língua, resta aos Estados ter que sempre lidar com "a questão da variabilidade", "a gestão da diversidade".

Nesse quadro, conforme apontaram De Fina e Perrino (2013), complica-se "a distinção 'micro-macro' pela introdução de distinções e dinâmicas de escala mais fina" (afinal, quem vive privilégios e desigualdades são pessoas agindo em múltiplos alinhamentos identitários), questiona-se "a visão de que comunidades de fala sejam relativamente homogêneas, compartilhando repertórios linguísticos e crenças, e presas a locais específicos" (afinal, alguém participa de uma única comunidade de práticas monolíngue?); enfatiza-se a "tensão entre homogeneização e diferenciação nas práticas, ideologias e identidades de linguagem" (afinal, quem não age nas disputas que se dão no terreno na linguagem?); e assim avança "a reavaliação crítica da concepção padrão de línguas como códigos que podem ser facilmente separados um/a de outro/a e que estão ancorado/as em comunidades de fala distintas e estanques" (p. 510). Entendemos que este dossiê avança nessa trilha principalmente pelo exame de casos de mercantilização de linguagem.

Simone da Costa Carvalho abre o dossiê com o artigo "Mercantilização da linguagem na promoção do turismo de luxo na Selva Iryapú (Misiones, Argentina): autenticidade, deslocamentos e resistência". Além de uma elucidativa revisão da literatura sobre a mercantilização da linguagem na promoção do turismo, Carvalho enfoca os usos da linguagem na exploração de turismo de luxo no lado argentino da área natural próxima às Cataratas do Iguaçu. Em detalhado estudo de caso, mostra como redes hoteleiras nacionais e internacionais se valem de recursos da língua e da cultura dos indígenas guaranis para gerar valor agregado a produtos e serviços turísticos, produzindo lucro que não é compartilhado com as comunidades locais. Ressalte-se nesta contribuição ao dossiê a importância de elementos de linguagem para dar selo de autenticidade no consumo de experiências. Examinando a difícil posição dos guaranis entre a necessidade e a resistência, contudo, Carvalho aponta que, diferentemente de casos análogos discutidos na literatura, em que a mercantilização da linguagem se apresenta como potencializadora da agentividade dos sujeitos em grupos minoritários, os habitantes originais da Selva Iryapú se veem obrigados a entrar em relação de exploração e alienação capitalista com os empreendedores.

Tendo por campo um município do Oeste do Paraná não longe dali, Neiva Maria Jung e Regina Coeli Machado e Silva examinam também como índices de linguagem, na forma de toques de alemão em repertório multifacetado, indiciam autenticidades complexas, inicialmente para promover consumo de experiências e agregar valor a produtos numa festa comunitária local promovida anualmente. Em "Deutsches Fest: vergonha e orgulho em um evento de mobilizações simbólicas e econômicas", as autoras percebem não apenas identidade (orgulho) passando a valor comercial (lucro), mas, mais surpreendentemente, lucro retornando em orgulho. O sucesso do empreendimento parece proporcionar aos promotores da festa e à parcela dos moradores locais que são descendentes de imigrantes de língua alemã chegados ao Rio Grande do Sul no século XIX, eles próprios migrados para o Paraná na década de 1960, superar a "vergonha" de ser "colono", pela celebração de satisfação em serem os "legítimos" representantes do valor local, agora mercantilizado e idealizado em associação com uma suposta origem na Alemanha contemporânea. Mobilizações simbólicas e econômicas de repertório linguístico outrora estigmatizado aparecem tanto na promoção do evento turístico comercial local, tal como poderíamos prever, quanto também promovem discursos de orgulho pelo pertencimento a uma "cultura alemã local", ecoando indicialização de celebração da branquitude em dinâmica muito particularmente local e contemporânea.

Natália Barroncas da Fonseca examina desdobramentos recentes do bem conhecido caso do ex-técnico de futebol da seleção nacional da África do Sul em "Repertório linguístico reconfigurado para lucro no caso Joel Santana". Bem além de ilustrar a repercussão de uso de inglês "truncado", Fonseca revela como até mesmo contradições na atribuição de valor a itens de repertório linguístico para a mercantilização de linguagem na contemporaneidade podem ser mobilizados para impelir a venda de serviços mediante recurso a performances midiáticas cômicas. A análise que faz de campanhas publicitárias em que o técnico teve participação como garoto propaganda, principalmente na muito bem-sucedida promoção de uma marca de produtos de higiene pessoal para público masculino, mostra como os 
repertórios linguísticos marcados podem ser mercantilizados em larga escala em aproveitamento das contradições na atribuição de valor a itens de repertório linguístico. Trata-se de um caso de lucro realizado mediante mercantilização de repertório linguístico que em outras ocasiões era visto como moeda podre.

A atenção tácita mas sistemática à garantia e maximização do valor dos diversos itens de repertório para a vida futura da prole de famílias transnacionais coreanas residentes no estado de São Paulo é o foco de Tatiana Martins Gabas em "A língua coreana como recurso em famílias transnacionais: tensões entre ideologias de linguagem". Para além de relatar como as mães que entrevistou avaliam o uso da língua coreana pelos filhos e tomam providências para o fortalecimento e o ensino da língua no ambiente familiar durante o período final de estadia no Brasil, Gabas empreende admirável autorreflexão sobre as suas próprias ideologias de linguagem nacionalistas como pesquisadora, tornadas evidentes pela surpresa que lhe causou a articulação marcada mais por discursos de lucro do que de orgulho que as mães fazem de suas planificações.

Pablo Albertoni por sua vez enfoca um caso de mercantilização de linguagem menos bem-sucedido e ainda em processo, que, como muitos, esbarra em contradições entre os regimes ideológicos mais ou menos nacionalistas de antes e de agora. Albertoni mostra como a produção de autenticidade muitas vezes crucial para a mercantilização é processo complexo, movido por possibilidades diversas e incertas de recompensa cujo sucesso não é garantido de antemão. Lembra-nos assim, como apontam Cavanaugh e Shankar (2014), que é preciso observar o "processo em cadeia da commodity"13, de toda a mercantilização de linguagem de que estamos tratando, isto é, "o arco dialético de atividades pelo qual um objeto adquire valor de mercado, pela via da sua produção, criação da marca, circulação e consumo" (p. 62) e assim tomar "as práticas de linguagem e as formas materiais que fazem parte desses esforços [...] como práticas laborais essenciais, [...] assim como o extenso trabalho e esforço que envolve a tentativa de tornar algo autêntico" (p. 60-61). Se custa tanto, deve valer a pena; resta saber para quem. Em "Mercantilização e autenticidade na fronteira uruguaio-brasileira: o portunhol no século XXI", Albertoni mostra como intelectuais e artistas se movem para que a UNESCO venha a reconhecer como patrimônio cultural imaterial o portunhol do norte do Uruguai, falado por populações em geral de classe trabalhadora rural. A autenticidade dos promotores da causa passa a ser uma questão central quando se trata de "celebrar" (para lucro?) o multilinguismo de populações cujo repertório antes estigmatizado precisa ser registrado ("autenticado") mediante os antigos modos de legitimação das línguas nacionais (padronização, normalização), que os falantes autênticos parecem rejeitar. Fica evidente assim nesse caso as inflexões de classe social no eixo de tensão entre autenticidade e mercantilização, requisito para garantir o valor de lucro de repertórios estigmatizados na nova economia globalizada.

Em "Essa mesma arma contra eles': Capitalismo, poder, linguagem e educação indígena", Carlos Maroto Guerola e Maria Inêz Probst Lucena desnudam um episódio de enfrentamento bem-sucedido, na constante estratificação e categorização para a legitimação da desigualdade, em que lideranças indígenas guaranis fazem frente a exigências de instâncias de poder estatal para a elaboração de documentos escolares protocolares, mas simbolicamente insidiosos. No que os autores chamam de obediência subversiva, vemos sucesso de resistência pelo diálogo inteligente da liderança educacional indígena com as autoridades burocráticas com vistas a garantir educação escolar indígena que faz bom sentido educacional e ainda assim recebe acreditação, e aí algum alento em práticas de reexistência nas periferias do capitalismo.

Com efeito, em "'Favela não se cala': mercantilização, materialidade e ideologia da linguagem na cooperação transperiférica", Daniel do Nascimento e Silva trata de respostas sutis - de agentes sociais situados nas periferias urbanas - à mercantilização de direitos e bens comuns. Observando a reflexividade de ativistas de movimentos sociais da África do Sul e do Rio de Janeiro sobre a mercantilização de recursos comunicativos no capitalismo, revisa e interpela as posições de autores críticos da noção de mercantilização da linguagem, como David Block, Marnie Holborow, William Simpson e John O’Regan, que argumentam que só se pode falar de mercantilização de linguagem no plano metafórico. Situa assim mais amplamente o percurso de reflexão sobre mercantilização da linguagem empreendido pelos autores dos demais artigos do dossiê no quadro amplo da fortuna crítica do pensamento de partida.

\footnotetext{
13. Optamos por manter o termo original em inglês aqui para sinalizar o vínculo entre o nosso tema mais amplo, mercantilização (commodification), isto é, a transformação de algo em mercadoria (e não uma venda), e "commodities", os bens que podem ser avaliados em termos de seu valor de troca, muitas vezes em processos que envolvem crucialmente elementos linguísticos como signos de valor, no que estamos referindo como mercantilização de linguagem (ver HELLER; DUCHÊNE, 2016; e SILVA, neste dossiê).
} 
A reflexão ampliada sobre os temas do dossiê se faz em contraponto na entrevista que Vanessa de Oliveira Andreotti, colega que atua na Universidade da Colômbia Britânica, Canadá, concedeu às colegas Jhuliane Evelyn da Silva e Clarissa Menezes Jordão, da Universidade Federal do Paraná (UFPR). Em "Nossa casa está caindo... e agora, Vanessa? Capitalismo, decolonialidade e futuros re-imaginados", buscam-se diálogos entre os quadros de perspectivas críticas que pautam os artigos do dossiê e os mais expressamente decoloniais. Mais ainda, vislumbra-se alguma boa esperança, que talvez precise ser inventada e, para não ser mais um conceito da branquitude alarmada, conquistada com ativismo (PERLEY, 2021), com alguma "'esperança radical', enraizada na ação e informada por quem sobreviveu traumas" (FINE; LOVE-NICHOLS, 2021, p. 13). Para tanto, tal como apontam Heller e McElhinny (2017, p. xiii-xv, 257-261), essa interlocução sugere atenção ao que está acontecendo no quadro histórico e político-econômico, e trabalho para tornar possível algum futuro de paridade participativa, destacando-se discursos alternativos ao capitalismo, como de certo nos oferecem as indigeneidades, com que afinal temos o privilégio (mais um!) de poder conviver. Afinal, como diz Andreotti, estamos todos num jogo em que tanto jogamos quanto somos jogados, mas alguns de nós têm mais experiência nessa empreitada e talvez lhes sobre ainda generosidade.

Saudando os 30 anos da Associação de Linguística Aplicada do Brasil (ALAB), confiamos que este dossiê possa fazer uma contribuição singela e crítica, ao reunir os trabalhos dos autores dos artigos e nossas interlocuções para articular o que entendemos sobre casos de mercantilização da linguagem no capitalismo tardio e assim gerar mais inteligibilidades sobre a vida contemporânea e sobre a linguagem como terreno de disputas e de produção de desigualdades a compreender e desafiar.

\section{REFERÊNCIAS}

ANDERSON, B. (2006[1983]). Imagined communities: Reflections on the origin and spread of nationalism. Londres: Verso. [Tradução brasileira: Anderson, B. (2008). Comunidades imaginadas (D. Bottman, Trad.). São Paulo: Companhia das Letras.]

BAUMAN, R.; BRIGGS, C. L. (2003). Voices of modernity: Language ideologies and the politics of inequality. Cambridge, RU: Cambridge University Press.

BLOCK, D. (2017). Political economy in applied linguistics research. Language Teaching, v. 50, n. 1, p. 32-64.

BLOCK, D. (2018). Political economy and sociolinguistics: Neoliberalism, inequality and social class. Londres/Nova Iorque: Bloomsbury Publishing.

BLOCK, D.; GRAY, J.; HOLBOROW, M. (2012) (orgs.). Neoliberalism and applied linguistics (p. 1-13). Nova Iorque: Routledge.

BLOMMAERT, J.; RAMPTON, B. (2011). Language and superdiversity. Diversities, v. 13, n. 2, p. 1-21.

CAVANAUGH, J. R.; SHANKAR, S. (2014). Producing authenticity in global capitalism: Language, materiality, and value. American Antbropologist, v. 116, p. 51-64.

CHUN, C. W. (2017). Discourses of capitalism: Everyday Economists and the Production of Common Sense. Oxon, Ru/Nova Iorque: Routledge.

DE FINA, A.; PERRINO, S. (2013). Transnational identities. Applied Linguistics, v. 34, n. 5, p. 509-515.

DUCHÊNE, A.; HELLER, M. (orgs.). (2012). Language in late capitalism: Pride and profit. Nova Iorque: Routledge.

FINE, J. C.; LOVE-NICHOLS, J. (2021). Language and climate justice: A research agenda. Journal of Sociolinguistics. Publicação eletrônica antecipada. (DOI: https://doi.org/10.1111/josl.12469)

FIORIN, J. L.; PETTER, M. (2008). Prefácio. In: África no Brasil: a formação da língua portuguesa. São Paulo: Contexto, p. 7-12.

FRASER, N. (1996). Social justice in the age of identity politics: Redistribution, recognition, and participation. Conferência na Universidade Stanford. The Tanner Lectures on Human Values. Disponível em: < https://tannerlectures.utah.edu/_documents/ a-to-z/f/Fraser98.pdf $>$. 
GAL, S.; IRVINE, J. T. (2019). Signs of difference: Language and ideology is social life. Cambridge, RU: Cambridge University Press.

HARVEY, D. (2005). A brief bistory of neoliberalism. Oxford, RU: Oxford University Press.

HARVEY, D. (2014). Seventeen contradictions and the end of capitalism. Oxford, RU: Oxford University Press.

HELLER, M. (2002). Globalization, the new economy and the commodification of language and identity". Journal of Sociolinguistics, v. 7 , n. 4 , p. $473-492$.

HELLER, M. (2005). Language, skill and authenticity in the globalized new economy. Revista de Sociolinguiistica, v. 2.

HELLER, M. (2010). The commodification of language. Annual Review of Antbropology, v. 39, p. 101-14.

HELLER, M. (2011). Patbs to post-nationalism: A critical etbnograpby of language and identity. Oxford: Oxford University Press.

HELLER, M.; MCELHINNY, B. (2017). Language, capitalism, colonialism: toward a critical bistory. Toronto: University of Toronto Press.

HELLER, M.; DUCHÊNE, A. (2012). Pride and profit: Changing discourses of language, capital and nation-state. In: A. Duchêne; M. Heller (orgs.), Language in late capitalism: Pride and profit. Nova lorque: Routledge, p. 1-21.

HELLER, M.; DUCHÊNE, A. (2016). Treating language as an economic resource: Discourse, data and debate. In: N. Coupland (org.), Sociolinguistics: Theoretical debates. Cambridge, RU: Cambridge University Press, p. 139-156.

HELLER, M.; PIETIKÄINEN, S.; PUJOLAR, J. (2018). Critical sociolinguistics research methods. Nova Iorque: Routledge.

HOBSBAWM, E. (1990). Nations and nationalism since 1780. Cambridge, RU: Cambridge University Press. [HOBSBAWM, E. (1990). Nações e nacionalismo desde 1780: programa, mito e realidade. Tradução de M. C. Paoli e A. M. Quirino. São Paulo: Paz e Terra.]

IRVINE, J. (2021, 7-10 de junho). Revisiting theory and method in language ideology research [Conferência plenária]. E-Sociolinguistics Symposium 23. Hong Kong, China.

JAFFE, A. (2011). Critical perspectives in language-in-education policy: The Corsican example. In: McCarty, T. L. (org.), Ethnograpby and language policy. New York: Routledge, p. 205-229.

MOITA-LOPES, L. P. (2006). Linguística aplicada e vida contemporânea: problematização dos construtos que têm orientado a pesquisa. In: L. P. Moita-Lopes (org.), Por uma linguística aplicada indisciplinar. São Paulo: Parábola, p. 85-107.

MOITA-LOPES, L. P. (2013a). Ideologia linguística: como construir discursivamente o português no século XXI. In: L. P. Moita-Lopes (org.), Português no século XXI: ideologias linguísticas. São Paulo: Parábola, p. 18-52.

MOITA-LOPES, L. P. (2013b). Como e por que teorizar o português: recurso comunicativo em sociedades porosas e em tempos híbridos de globalização cultural. In: L. P. Moita-Lopes (Org.), Português no século XXI: ideologias linguísticas. São Paulo: Parábola, p. 101-119.

MOITA-LOPES, L. P. (2015). Introduction: Linguistic ideology: How Portuguese is being discursively constructed in late modernity. In: L. P. Moita-Lopes (org.), Global Portuguese: Linguistic ideologies in late modernity. Nova Iorque: Routledge, p. 1-26.https://doi.org/10.1111/josl.12465

OLIVEN, R. G.; GARCEZ, P. M. (2020). "A mudança social se desenrola conflituosamente no terreno da linguagem". Entrevista com Monica Heller (Professora da University of Toronto). Horizontes Antropológicos, v. 26, n. 57, p. 315-359. (DOI: https:// doi.org/10.1590/s0104-71832020000200011)

PERLEY, B. C. (2021). Dare we hope? Journal of Sociolinguistics. Publicação eletrônica antecipada. (DOI: https://doi.org/10.1111/ josl.12465) 
SIGNORINI, I. (2013). Política, língua portuguesa e globalização. In: L. P. Moita-Lopes (org.), Português no século XXI: cenário geopolítico e sociolinguístico. São Paulo: Parábola, p. 74-100.

SIGNORINI, I. (2015). Portuguese language globalism. In: L. P. Moita-Lopes (org.), Global Portuguese: Linguistic ideologies in late modernity. Nova Iorque: Routledge, p. 47-65.

URCIUOLI, B. (2008). Skills and selves in the new workplace. American Ethnologist, v. 35, n. 2, p. 211-228.

WILLIAMS, R. (1973). The country and the city. Londres: Chatto and Windus. [WILLIAMS, R. (1998). O campo e a cidade na bistória e na literatura. Tradução de Paulo Henriques Britto. São Paulo: Cia. das Letras.] 